\title{
Efficiency of a CVT Operated EVT Experimentally Evaluated against Half-Toroidal and Push-Belt CVTs
}

\author{
Joachim Druant, Hendrik Vansompel, Frederik De Belie and Peter Sergeant
}

\begin{abstract}
This article describes how an electrical variable transmission (EVT) can be used as alternative for mechanical continuously variable transmission (CVT) systems. An EVT is an electromagnetic power split device having two mechanical and two electrical ports. The speed ratio between both mechanical ports (rotors) can be varied in a continuously variable way, so that this machine can be used as electromagnetic alternative for the mechanical pushbelt and half-toroidal CVT. Its operating principle is based on splitting the power into an electromagnetic direct path and an electrical path involving two inverters connected back-to-back. Its potential use as CVT is investigated by comparing experimental data against toroidal and belt CVT data from literature having comparable power ratings. To this end measurements are performed on a prototype 120 $\mathrm{kW}$ permanent magnet EVT.
\end{abstract}

Index Terms-Continuously variable transmission, Efficiency, Electrical variable transmission

\section{INTRODUCTION}

$\mathbf{I}$ $\mathrm{N}$ automotive applications the most well-known continuously variable transmissions (CVTs) are the metal belt drive CVT and the half-toroidal traction drive CVT [1]. Of these transmissions, the belt version has proven to increase driving comfort and decrease fuel consumption with $5-15 \%$ on average when compared to stepped automatic transmissions [2]. Therefore this transmission can be seen as the industry benchmark. Nevertheless, these mechanical systems can have some critical issues. Both CVT systems transmit torque based on mechanical contacts, inducing slip and friction. This requires lubrication and the need for traction fluid to transmit torque between metal parts [3], [4]. The gear ratio is restricted due to geometrical constraints of the design, requiring a clutch or torque converter to achieve standstill [5] and a reverse unit to change rotation direction. Furthermore, changing the gear ratio is often slow, and can cause additional wear [6].

Electromagnetic systems on the other hand could offer the advantage of reduced maintenance and higher efficiency

Manuscript received May 02, 2017; revised July 14, 2017 and August 24, 2017; accepted September 13, 2017. This work was financed by the Research Foundation-Flanders (FWO). J. Druant was awarded a Ph.D. Fellowship from the FWO in 2014 (email: Joachim.Druant@ugent.be). J. Druant, H. Vansompel, F. De Belie, and P. Sergeant are with the Electrical Energy Laboratory of the Department of Electrical Energy, Metals, Mechanical Constructions and Systems of Ghent University, B9000 Ghent, Belgium and with Flanders Make, the strategic research center for the manufacturing industry.

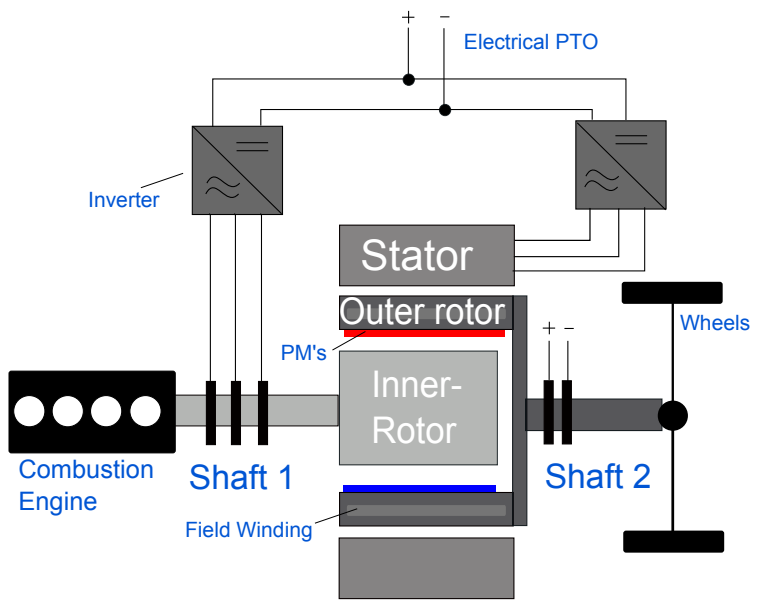

Fig. 1: Schematic of a permanent magnet EVT used as CVT between combustion engine and wheels.

due to the absence of sliding contacts, pumping systems for lubrication and actuation, as well as the absence of a torque converter or reversing unit. Additionally, faster dynamics can be expected inherent to electrical drives. A diesel-electric transmission for instance consists of an electrical generator, a controlled rectifier, and one or multiple inverters and electrical motors. This principle is nowadays used in traction drives for ships, trains and heavy duty machinery [7]-[9]. Its main disadvantage is that the full output power needs to be converted by two electrical machines and two power electronic converters at least.

Other electromagnetic CVT systems try to overcome this drawback by combining a planetary gear set with two electrical machines [10], [11]. This system has the advantage that part of the input power is directly transferred to the output shaft, while only a part is converted in an electrical way. In other papers an alternative solution is proposed to improve the compactness and cost-effectiveness of the system by replacing the two electrical machines by one double rotor machine as in [12][14]. However, all previously mentioned solutions still require a mechanical gear box.

The double rotor electromagnetic CVT described in this paper also converts only a fraction of the input power through the inverters, while avoiding the use of a planetary gear set. The system is based on an electrical variable transmission (EVT), previously described in [15], and which can be seen as an electrical machine having two concentric rotors, as is 
schematically shown in Fig. 1. The stator and inner rotor are hereby often equipped with a three-phase winding, each supplied by its own inverter. To supply the rotating rotors, slip rings are needed. The inverters are connected to a common dcbus, supported by a dc-bus capacitor system. The outer rotor can be designed as a cage [16]-[18], PM rotor [19]-[23] or a combination of PMs with a dc-field winding [24], [25] as is the case in this paper. Calculations for an EVT used as power split device with storage and applied within a hybrid electric vehicle (HEV) are given and discussed in [26]-[29] where the focus is merely on the higher system level control. In this paper, the machine is considered without battery storage and the dc-bus is used to power additional equipment. Before introducing efficiency data of the EVT, there is the requirement of describing the operating principle of the machine used as CVT with focus on torque generation of different EVT parts and power flow within the machine and inverters. This is done in the first part of this paper. Next, the experimental EVT setup is introduced and efficiency and power flow measurements are given to support the theoretical conclusions. Finally the EVT performance is compared against results for belt and toroidal CVT data as given in the literature.

\section{Electrical Variable transmission}

\section{A. Topology}

A one pole pair cross section of the EVT, under consideration in this paper, is given in Fig. 2 where both rotors and stator can be seen. Both the stator and inner rotor windings are supplied by an inverter connected back-to-back to a common dc-bus. The outer rotor contains a combination of permanent magnets and a dc-field winding as done in [24], [25].

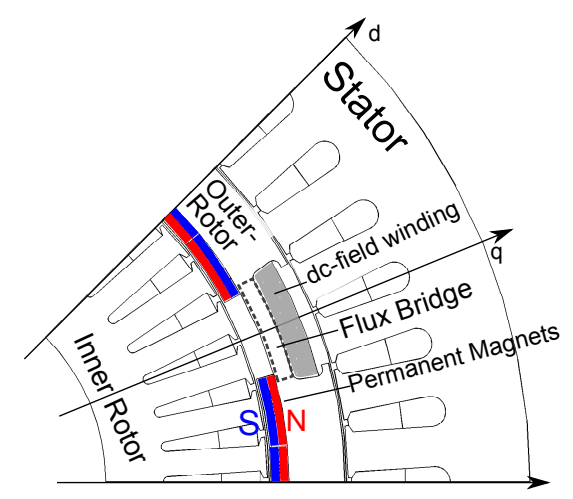

Fig. 2: Cross sectional view of the EVT, showing the stator (index s), outer rotor (index r2) and inner rotor (index r1).

The dc-field winding in combination with a flux bridge allows to change the stator flux linkage. The stator windings are used whenever there is torque difference between both shafts as will be described in section IV. This is particularly the case in case of acceleration from standstill, during which high stator torques are required. However, if the torque difference between both shafts is sufficiently low, as is the case in the direct drive region, only limited stator torque is required. During such time intervals, often long, it is more efficient to link a small amount of the PM flux with the stator, hence reducing the iron losses in the stator. Also, since modulation of the stator magnetic field is performed with help of the dc-field winding, rather than by the stator currents, a smaller stator inverter can be used.

\section{B. Principle of Operation}

In this subsection the working principle of the machine is described based on simple power flow equations, and by neglecting the losses in the machine as mentioned in [15], [30], [31]. Despite the approximations made, these equations provide a very good understanding of the operation of the machine in different operating points. The equations are elaborated here for an EVT without battery storage. Also the effect of power take-off (PTO) on the power flow within the machine is shown.

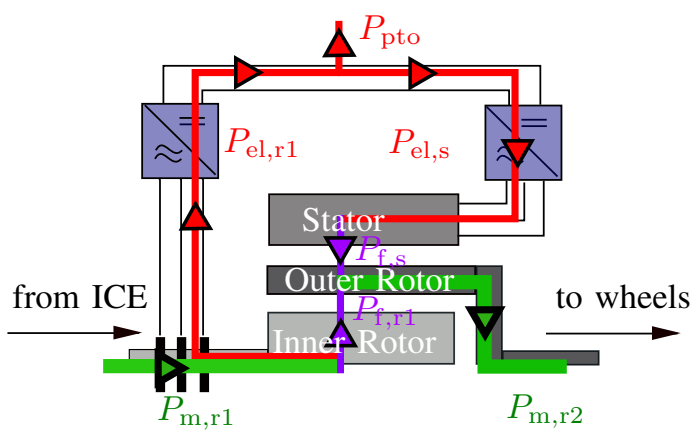

Fig. 3: Power paths and sign conventions. As an illustration, the outer rotor speed equals half of the input speed.

In the case of an HEV, the inner rotor of the EVT is mostly connected to the ICE, while the outer rotor is connected to the final drive, as is the case in Fig. 3. In this figure, the sign conventions for a positive power flow are given. The electromagnetic torque $T_{\mathrm{r} 2}$ on the outer rotor shaft is the sum of two contributions. First, there is the electromagnetic torque interaction from the stator onto the outer rotor, denoted by $T_{\mathrm{s}}$ in this paper. Next, there is the torque interaction from the inner onto the outer rotor, denoted by $T_{\mathrm{r} 1}$ :

$$
T_{\mathrm{r} 2}=\left(T_{\mathrm{s}}+T_{\mathrm{r} 1}\right)
$$

The product of torque and speed of the inner rotor shaft equals the mechanical input power $P_{\mathrm{m}, \mathrm{r} 1}=T_{\mathrm{r} 1} \Omega_{\mathrm{r} 1}$ to the EVT. This is, if losses are neglected, converted to electrical power $P_{\text {pto }}$ and to mechanical power $P_{\mathrm{m}, \mathrm{r} 2}=T_{\mathrm{r} 2} \Omega_{\mathrm{r} 2}$.

$$
T_{\mathrm{r} 1} \Omega_{\mathrm{r} 1}=P_{\text {pto }}+T_{\mathrm{r} 2} \Omega_{\mathrm{r} 2}
$$

The ratio between input and output speed is hereby continuously variable. Depending on the speed ratio between both rotors and the required PTO, the power flow distribution within the machine itself will change. The mechanical power $P_{\mathrm{m}, \mathrm{r} 1}$ is hereby split into two parts when entering the EVT. The part

$$
P_{\mathrm{f}, \mathrm{r} 1}=T_{\mathrm{r} 1} \Omega_{\mathrm{r} 2}
$$


is, as shown in Fig. 3, directly transferred to the outer rotor shaft by means of the electromagnetic torque $T_{\mathrm{r} 1}$ exerted by the inner rotor on the outer rotor rotating at angular speed $\Omega_{\mathrm{r} 2}$. The remaining part

$$
P_{\mathrm{el}, \mathrm{r} 1}=T_{\mathrm{r} 1}\left(\Omega_{\mathrm{r} 1}-\Omega_{\mathrm{r} 2}\right)
$$

is converted electrically by means of the inverter connect to the inner rotor. Combining (2) with (4) yields:

$$
P_{\mathrm{el}, \mathrm{r} 1}=P_{\mathrm{m}, \mathrm{r} 2}\left(1-\frac{\Omega_{\mathrm{r} 2}}{\Omega_{\mathrm{r} 1}}\right)+P_{\mathrm{pto}}\left(1-\frac{\Omega_{\mathrm{r} 2}}{\Omega_{\mathrm{r} 1}}\right)
$$

The stator electrical power $P_{\mathrm{el}, \mathrm{s}}$ equals the inner rotor electrical power $P_{\mathrm{el}, \mathrm{r} 1}$ from (5) minus the electrical PTO:

$$
P_{\mathrm{el}, \mathrm{s}}=P_{\mathrm{m}, \mathrm{r} 2}\left(1-\frac{\Omega_{\mathrm{r} 2}}{\Omega_{\mathrm{r} 1}}\right)-P_{\mathrm{pto}} \frac{\Omega_{\mathrm{r} 2}}{\Omega_{\mathrm{r} 1}}
$$

The power split in (5) and (6) shows that only a fraction of the mechanical power is converted in an electrical way.

\section{INVERTER RATING}

As can be seen in (5) and (6), the electrical power flowing through the inverters is the superposition of two terms shown in Fig. 4a and Fig. 4b respectively. The first part is related to the mechanical power $P_{\mathrm{m}, \mathrm{r} 2}$ of the outer rotor, while the second part is related to the power take-off $P_{\text {pto }}$.

As shown in Fig. 4a only part of the mechanical power converted by the EVT is converted in an electrical way, depending on the speed difference between both rotors. The remaining part of the power is converted in an electromagnetic way denoted by $P_{\mathrm{f}, \mathrm{r} 1}$ in Fig. 3 due to electromagnetic torque between both rotors rotating at different speed. This way the rated inverter power can be a fraction of the rated mechanical power of the machine. Note that the mechanical power $P_{\mathrm{m}, \mathrm{r} 2}$ at zero speed $\Omega_{\mathrm{r} 2}$ is zero as well in Fig. 4a so that the absolute value of the electrical power will reach a maximum in $\Omega_{\mathrm{r} 1} \in\left[0, \Omega_{\mathrm{r} 2}\right]$. This will be illustrated in subsection $\mathrm{V}-\mathrm{C}$ where the experimentally measured power flows are shown. As for the PTO, both inverters need to be able to convert

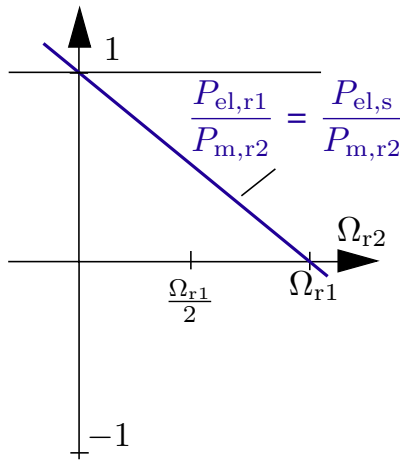

(a) $P_{\text {pto }}=0$

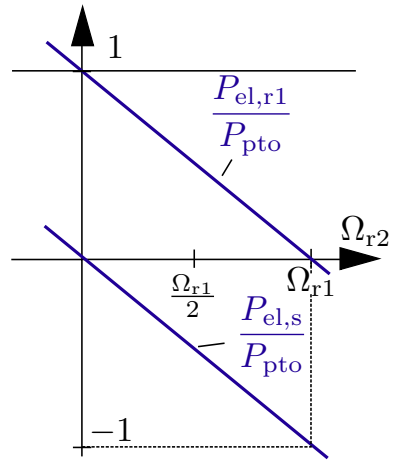

(b) $P_{\mathrm{m}, \mathrm{r} 2}=0$
Fig. 4: Power converted by inverters connected to stator and inner rotor due to (a) mechanical power at output and (b) due to power take-off. the full PTO power as can be seen in Fig. 4b. At low speed PTO is performed by the inverter connected to the inner rotor, while at higher speeds, more and more power is converted by the inverter connected to the stator. The power relations of Fig. 4 can be superimposed to know the resulting inverter power for stator and inner rotor. With the presence of PTO the inner rotor electrical power increases according to (5), while the stator electrical power decreases since both power terms in (6) partially cancel out. Note that this argumentation is only valid for $\Omega_{\mathrm{r} 1} \in\left[0, \Omega_{\mathrm{r} 2}\right]$. At negative $\left(\Omega_{\mathrm{r} 2}<0\right)$ and supersynchronous $\left(\Omega_{\mathrm{r} 2}>\Omega_{\mathrm{r} 1}\right)$ speeds, circulating power terms are present, increasing the electrical power conversion by the inverters, even beyond $P_{\mathrm{m}, \mathrm{r} 2}$ and $P_{\mathrm{pto}}$.

\section{TORque RATING}

In practice, the torque on both rotors of the EVT is controlled, rather than the power flow that is a result of torque and speed. At given speeds of both rotors, the outer rotor torque $T_{\mathrm{r} 2}$ can be controlled resulting in a power $P_{\mathrm{m}, \mathrm{r} 2}$ to the wheels. This outer rotor torque is the result of the electromagnetic torque contributions related to stator $T_{\mathrm{s}}$ and inner rotor $T_{\mathrm{r} 1}$ as was given in (1).

\section{A. Torque contributions}

The inner rotor torque $T_{\mathrm{r} 1}$ loads the ICE, and determines the mechanical input power to the EVT. This torque thus cannot be chosen independently, but is controlled by a dc-bus controller so that at any time the power balance:

$$
P_{\mathrm{m}, \mathrm{r} 1}=P_{\mathrm{m}, \mathrm{r} 2}+P_{\mathrm{pto}}+P_{\mathrm{loss}}
$$

or

$$
T_{\mathrm{r} 1} \Omega_{\mathrm{r} 1}=T_{\mathrm{r} 2} \Omega_{\mathrm{r} 2}+P_{\mathrm{pto}}+P_{\text {loss }}
$$

is full-filled. $P_{\text {loss }}$ represents the losses generated within the EVT and inverters, and is discussed later on in subsection V-B. The stator torque $T_{\mathrm{s}}$ is added to the inner rotor torque $T_{\mathrm{r} 1}$ to result in the desired outer rotor torque $T_{\mathrm{r} 2}$, as was given in (1):

$$
T_{\mathrm{s}}=T_{\mathrm{r} 2}-T_{\mathrm{r} 1}
$$

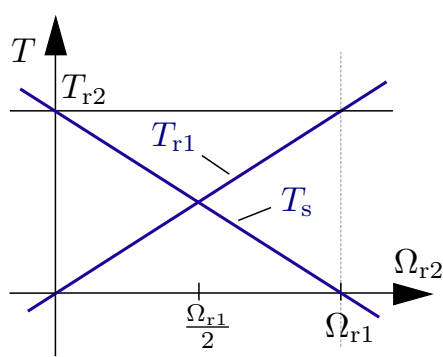

(a) $P_{\text {pto }}=0$

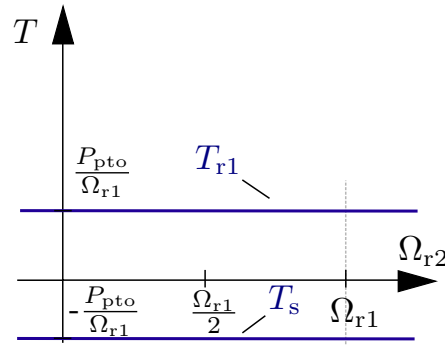

(b) $P_{\mathrm{m}, \mathrm{r} 2}=0$
Fig. 5: Electromagnetic torque produced by stator and inner rotor windings due to (a) torque to outer rotor shaft and (b) due to power take-off. 
With the inner rotor torque known from the dc-bus controller (8), the stator torque thus determines the resulting torque on the outer rotor. The torque relations are graphically given in Fig. 5. In Fig. 5a the torque on inner rotor and stator, resulting from a torque demand on the outer rotor, are given. In Fig. 5b the effect of PTO is shown. Both figures can be superimposed to know the resulting torque on stator and inner rotor if losses are ignored. Whenever the power balance of (8) is not fullfilled, a net power will be withdrawn from or sent to the dcbus capacitors. To this end, it is advised to add a small energy buffer.

\section{B. Practical Implementation}

The torque can be controlled by imposing appropriate currents through stator, inner and outer rotor windings. To control the torque on both rotors of the EVT, there are five independent current components to be controlled. Those are the stator $\mathrm{q}$ - and $\mathrm{d}$-axis currents, the inner rotor $\mathrm{q}$ - and $\mathrm{d}$ axis currents and the outer rotor dc-field current as can be seen in Fig. 2. Many combinations of currents thus yield the same torque, while the losses will be different for every set of currents. To this end, a torque controller is developed that calculates for every set of torque and speed values the optimal set of currents that minimizes the copper and iron losses in the machine [32]. It turns out that at low speed of the outer rotor, the stator current can optimally be controlled at constant load angle of about $120^{\circ}$ with the PM-flux vector. The outer rotor dc-current is hereby set to increase linearly with the stator torque $T_{\mathrm{s}}$. For the inner rotor finally, a constant load angle of $90^{\circ}$ is optimal. At higher speeds, the stator flux is weakened by modifying the load angle and using the dc-field current.

\section{EfFICIENCy MEAsurement and Loss SEPARATION}

\section{A. Demonstrator EVT}

The relations, given in previous section, give the lossless working principle for a general EVT system. A schematic of the machine, under consideration in this paper, was given previously in Fig. 2. The corresponding experimental set-up in the lab is shown in Fig. 6, along with some electrical and geometrical machine parameters in Table I. The weight of this specific EVT prototype is about $115 \mathrm{~kg}$. The overall length of this specific prototype machine with bearings, sliprings and casing included is $40 \mathrm{~cm}$. For the measurements, $100 \mathrm{Nm}$ torque sensors with an accuracy class of $0.1 \%$ have been used.

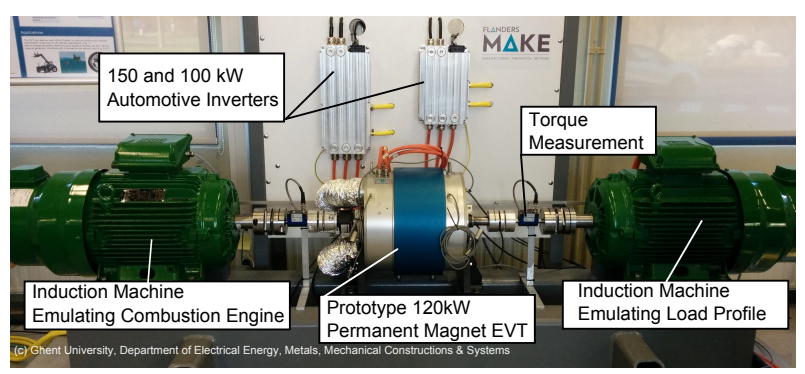

Fig. 6: Experimental set-up
TABLE I: MACHINE PARAMETERS

\begin{tabular}{lccc}
\hline & stator & outer rotor & inner rotor \\
\hline rated mechanical power [kW] & - & 120 & 75 \\
\hline rated current amplitude [A] & 265 & $4.6(\mathrm{dc})$ & 150 \\
\hline max speed [rpm] & - & 6000 & 6000 \\
\hline continuous torque [Nm] & 245 & 382 & 137 \\
\hline maximum torque* [Nm] & 410 & 652 & 242 \\
\hline number of pole pairs & 4 & 4 & 4 \\
\hline outer radius [mm] & 175 & 123.5 & 102 \\
\hline inner radius [mm] & 124.5 & 103 & 57 \\
\hline active axial length [mm] & 87 & 87 & 87 \\
\hline inverter rating [kW] & 150 & - & 100 \\
\hline switching frequency [kHz] & 12 & - & 12 \\
\hline DC-link voltage [V] & 600 & - & 600 \\
\hline * Maximum torque based on $10 \mathrm{~s}$ current limit of installed inverters
\end{tabular}

* Maximum torque based on 10s current limit of installed inverters.

For the experiments, induction machines where used to control the speed $N_{\mathrm{r} 1}$ and $N_{\mathrm{r} 2}$ of inner and outer rotor shaft. Both machines are shown in Fig. 6 as well. The outer rotor torque $T_{\mathrm{r} 2}$ can be chosen independently, resulting in a desired mechanical power $P_{\mathrm{m}, \mathrm{r} 2}$ to the load. The inner rotor torque $T_{\mathrm{r} 1}$ on the other hand needs to be chosen as such that the input power from the ICE $P_{\mathrm{m}, \mathrm{r} 1}$ equals the output mechanical power $P_{\mathrm{m}, \mathrm{r} 2}$, the power take-off $P_{\text {pto }}$ and the losses $P_{\text {loss }}$ within inverters and EVT according to (8). This is done by a PI controller and by measuring the dc-current (power) to the common dc-bus of both inverters. A summary is given in the schematic of Fig. 7.

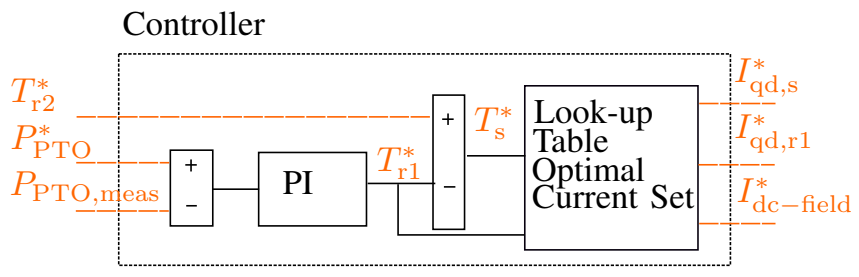

Fig. 7: Controller used for measurements.

\section{B. Measured Overall Steady-State Efficiency}

In this subsection, efficiency measurements on the demonstrator EVT are shown and discussed. Also, the different loss contributions are given, information that is valuable for further design optimizations. The results are shown in Fig. 8-10 for an input speed $N_{\mathrm{r} 1}$ of $1500 \mathrm{rpm}, 2000 \mathrm{rpm}$ and $3000 \mathrm{rpm}$ and for different outer rotor torque values. The torque values are limited by the torque sensors used to $100 \mathrm{Nm}$ on both shafts. The efficiencies are compared to a belt and toroidal mechanical CVT later on in subsection VI. As can be seen in the figures, the efficiency reaches a maximum if both rotors rotate at about the same speed. The reason is that at synchronous rotation and just before, the inverter loss, stator copper loss, the inner rotor iron loss and the friction losses of the bearings supporting the relative motion of the rotors reach a minimum as will be 


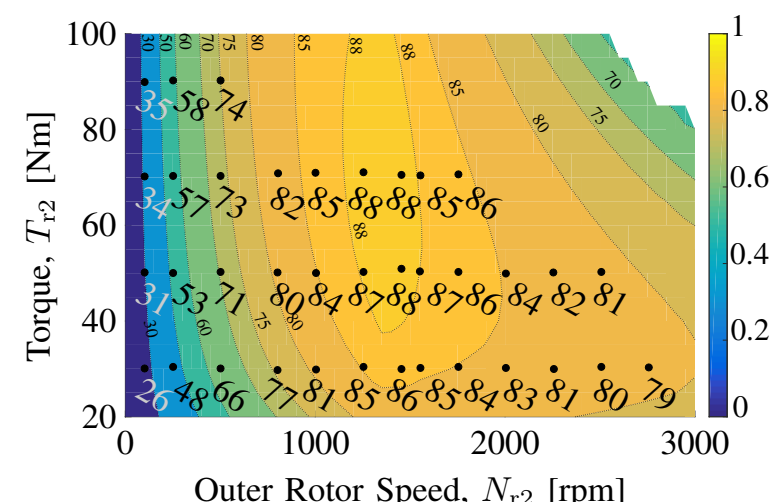

Outer Rotor Speed, $N_{\mathrm{r} 2}$ [rpm]

Fig. 8: Measured shaft to shaft efficiency at input speed $N_{\mathrm{r} 1}=1500 \mathrm{rpm}, P_{\text {pto }}=0 \mathrm{~W}$. Background color map represents simulation results.

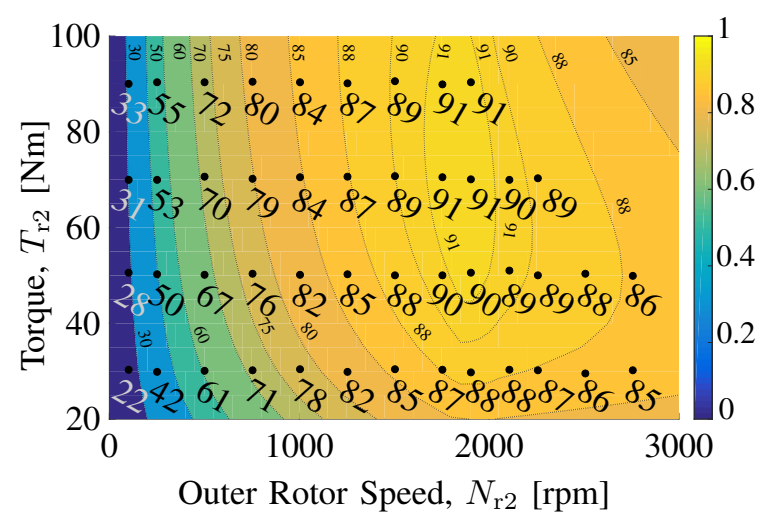

Fig. 9: Measured shaft to shaft efficiency at input speed $N_{\mathrm{r} 1}=2000 \mathrm{rpm}, P_{\text {pto }}=0 \mathrm{~W}$. Background color map represents simulation results.

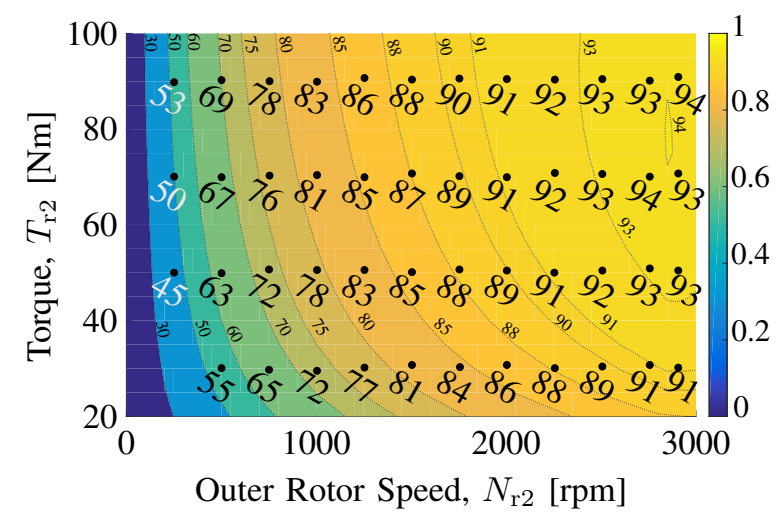

Fig. 10: Measured shaft to shaft efficiency at input speed $N_{\mathrm{r} 1}=3000 \mathrm{rpm}, P_{\text {pto }}=0 \mathrm{~W}$. Background color map represents simulation results.

shown in this subsection, where the different loss components are described into detail. Also shown in these figures are the predicted efficiencies from the loss models developed at the lab. The iron loss parameters from [33], [34] were hereby tuned based on no-load measurements. Also the bearing and slip ring friction loss has been identified on the setup to be used in the loss models. High efficiencies up to $94 \%$ have been measured.

In order to fully understand the evolution of the efficiency, the different loss contributions need to be considered. The power losses generated within an EVT have a different nature than is common in mechanical CVT systems. A method to calculate and measure the different loss components within an EVT has been given in [35].

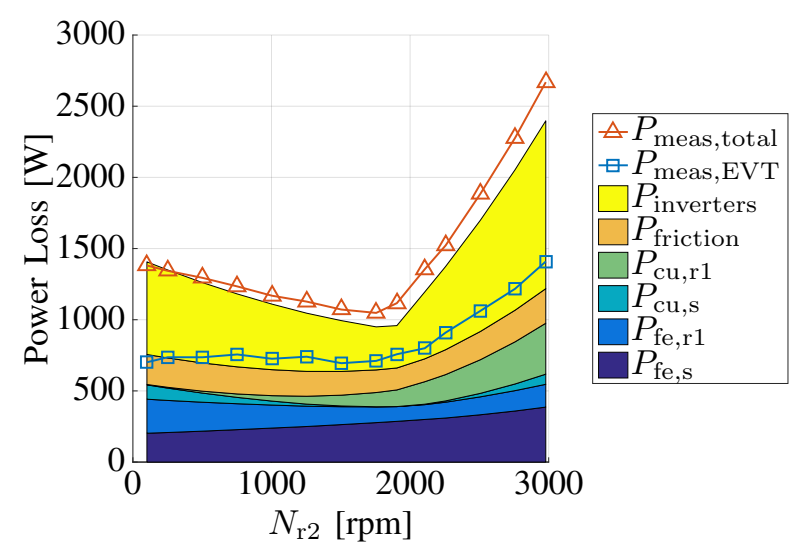

Fig. 11: Measured total and EVT machine losses at $T_{\mathrm{r} 2}=50$ Nm. Theoretical loss decomposition is shown as well. Input speed $N_{\mathrm{r} 1}=2000 \mathrm{rpm}, P_{\text {pto }}=0 \mathrm{~W}$.

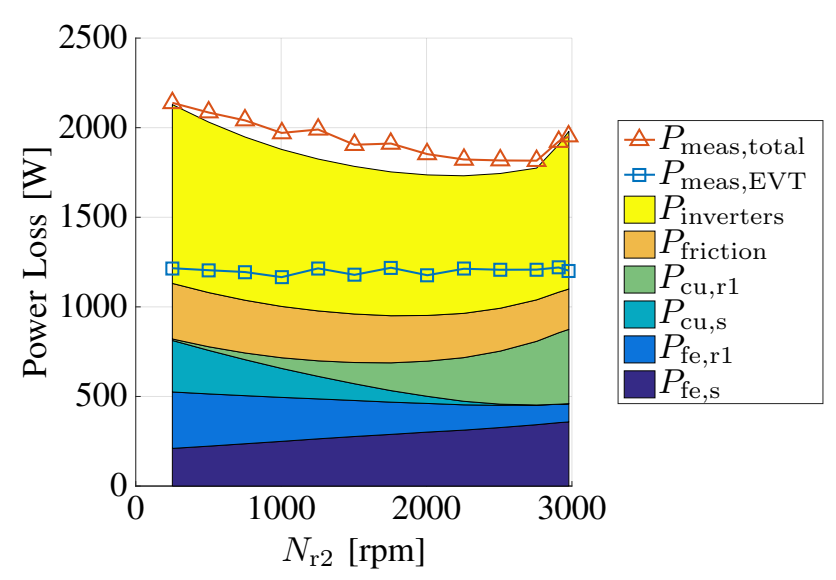

Fig. 12: Measured total and EVT machine losses at $T_{\mathrm{r} 2}=90$ $\mathrm{Nm}$. Theoretical loss decomposition is shown as well. Input speed $N_{\mathrm{r} 1}=3000 \mathrm{rpm}, P_{\mathrm{pto}}=0 \mathrm{~W}$.

A detailed analysis of the main loss components according to this technique for an EVT used as CVT is shown in Fig. 11 and Fig. 12. These figures show the total measured power loss $P_{\text {meas,total }}$ in EVT plus inverters in red, and the measured power losses $P_{\text {meas,EVT }}$ within the EVT machine in blue for two given operating points of outer rotor torque $T_{\mathrm{r} 2}$ and inner rotor speed $N_{\mathrm{r} 1}$. Also the theoretical loss decomposition is shown. The total measured power loss $P_{\text {meas,total }}$ is to be compared with the sum of all loss contributions. The measurement is the difference between mechanical power 
measurement at inner rotor and outer rotor shaft, and is in good accordance with the theoretically expected loss. The measured EVT loss $P_{\text {meas,EVT }}$ is the measured loss without inverters. This was possible by measuring the inner rotor and stator electrical power as well using a power analyzer. As was already concluded from the efficiency measurements shown in Figs. 8-10, the power losses reach a minimum near synchronous rotation of both rotors. To understand the evolution of the losses in Fig. 11 and Fig. 12, and thus efficiency in Figs. 8-10, the most important loss components are briefly discusses here:

- The inverter losses are the sum of the losses generated in both the inverters connected to stator and inner rotor, and mainly depend on the inverter current and thus electromagnetic torque produced by stator and inner rotor. From Fig. 5, it can be seen that from zero speed towards synchronous rotation, the torque $T_{\mathrm{s}}$ generated by the stator decreases, while the torque $T_{\mathrm{r} 1}$ generated by the inner rotor increases. This results in slightly decreasing inverter losses since the inverter connect to the stator has the higher losses. At supersynchronous operation, both torque components increase in absolute value (circulating power region) so that the total inverter losses increase when increasing the outer rotor speed.

- The same is true for the copper losses, that are a quadratic function of the torque. Indeed, the stator copper losses $P_{\mathrm{cu}, \mathrm{s}}$ decrease towards synchronisation of both rotors to increase again in the supersynchronous speed region. The inner rotor copper losses $P_{\mathrm{cu}, \mathrm{r} 1}$ increase quadratically with outer rotor speed, also in accordance with Fig. 5. Note that, when increasing the outer rotor torque, copper losses will become more and more dominant.

- The iron losses $P_{\mathrm{fe}}$ are the dominant loss term in the machine itself in the considered operating points. The stator iron loss increases with outer rotor speed $N_{\mathrm{r} 2}$ while the inner rotor iron loss is related to the speed difference $N_{\mathrm{r} 2}-N_{\mathrm{r} 1}$ between both rotors as is illustrated in Fig. 11 and Fig. 12

- Also the mechanical friction losses in the bearings and slip rings are shown. The loss related to the bearing, supporting the inner rotor, remains constant at constant inner rotor speed, as are the inner rotor slip ring friction losses. The loss of the bearings, providing the relative motion of the rotors, decreases towards synchronization of both rotors, while the outer rotor bearing loss increases.

All these considerations result in the net friction loss shown in the figures.

\section{Measured Power Flow}

Finally, in order to support the theoretical derivation in Section III, the corresponding electrical and mechanical power flow in the machine is given in Fig. 13.

The figures show, as theoretically expected in Fig. 4, that only part of the power is transmitted in an electrical way if the outer rotor speed $N_{\mathrm{r} 2}$ is lower than the inner rotor speed $N_{\mathrm{r} 1}$. The evolution of the electrical power as function of speed is a quadratic function. Indeed, the mechanical power

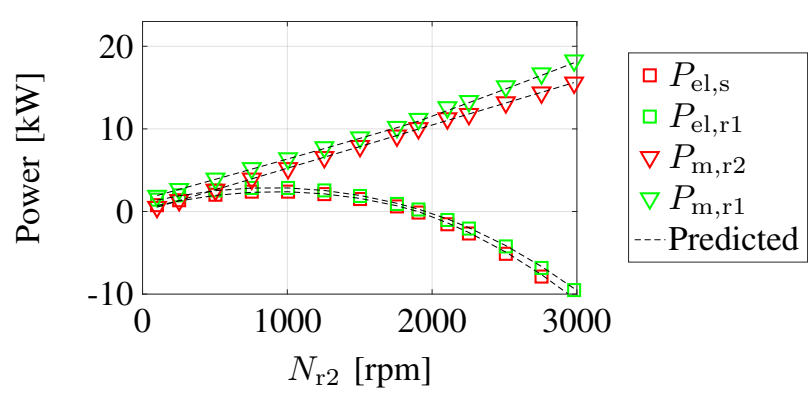

(a) $N_{\mathrm{r} 1}=2000 \mathrm{rpm}$

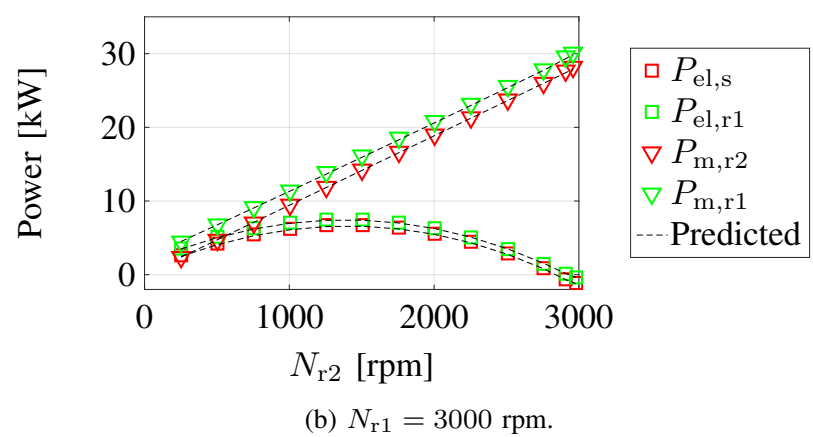

Fig. 13: Measured and predicted power flow at at $T_{\mathrm{r} 2}=90$ $\mathrm{Nm}$ and given input speed $N_{\mathrm{r} 1}$.

increases linearly, and the electrical power is a linear function of the mechanical power as shown in Fig. 4. Note that the difference between the input mechanical power $P_{\mathrm{m}, \mathrm{r} 1}$ and output mechanical power $P_{\mathrm{m}, \mathrm{r} 2}$ equals the sum of all loss components in the machine and inverters. The difference between the inner rotor electrical power $P_{\mathrm{el}, \mathrm{r} 1}$, and stator electrical power $P_{\mathrm{el}, \mathrm{s}}$ equals the inverter loss. The losses have been explained into detail in the previous subsection.

\section{EVT COMPARED TO MECHANICAL EQUIVALENT}

In order to situate the EVT performance with respect to other transmission systems, the machine is compared against measured mechanical CVT data in literature. In this paper a comparison is made by comparing measured efficiency data from a half toroidal [36], [37] and a push-belt CVT [38] with the measured EVT data from this paper having comparable system ratings and system volume. The half toroidal CVTs in [36] and [37] have a comparable maximum output torque as the EVT in the order of $350 \mathrm{Nm}$ and $430 \mathrm{Nm}$ respectively. For the belt CVT in [38], torque ratings up to $200 \mathrm{Nm}$ are reported only .

\section{A. Steady-State efficiency}

The measurements in [36]-[38] have some operating points in common to those used to obtain the steady-state efficiency measurements in this paper. Both data are shown in Fig. 14 and Fig. 15 for the half-toroidal and push-belt CVT respectively together with measurement data from the EVT. The efficiencies are plotted as function of the input torque $T_{\mathrm{r} 1}$ for different gear ratios $r_{\mathrm{g}}=\frac{N_{\mathrm{r} 2}}{N_{\mathrm{r} 1}}$. Note that these were the shaft-to-shaft 
efficiencies for which both machine and inverter losses are taken into account.

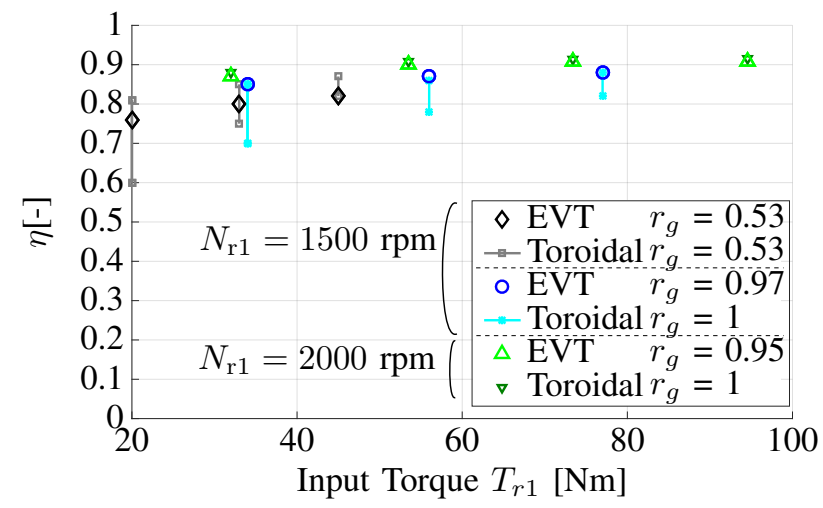

Fig. 14: Measured part load steady-state efficiency comparison between EVT and half-toroidal CVT from [37] at input speed $N_{\mathrm{r} 1}=1500 \mathrm{rpm}$ and [36] at input speed $N_{\mathrm{r} 1}=2000 \mathrm{rpm}$. Different gear ratios $r_{\mathrm{g}}$ are considered. Note that for the half-toroidal CVT no hydraulic pump losses were taken into account.

As can be seen in Fig. 14, the toroidal and EVT efficiencies are very similar in the operating points reported in literature. However, it has to be noted that for the toroidal CVT measurements only the variator losses are taken into account. This does not include losses for applying a clamping force on the variator and/or changing the tilting angle of the power rollers. Also, the power loss in an additional planetary gear set - required to have the same functionality as an EVT - is not accounted for.

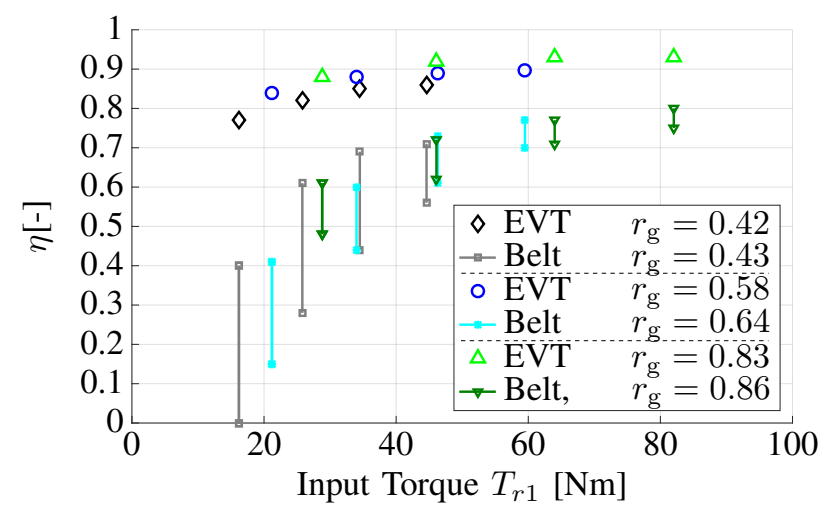

Fig. 15: Measured part load steady-state efficiency comparison between EVT at input speed $N_{\mathrm{r} 1}=3000 \mathrm{rpm}$ and push-belt CVT from [38] at input speed $N_{\mathrm{r} 1}=2865 \mathrm{rpm}$.

The pump losses are taken into account comparing the pushbelt efficiencies with the corresponding EVT efficiencies in Fig. 15, as are the variator torque and slip losses and the final reduction gear loss. As can be seen in this figure, the EVT has higher steady-state efficiencies in the operating points shown. The variation in the push-belt efficiency measurement is due to the slip control. The lower limit represents the standard slip control used in a commercial belt CVT, while for the upper efficiency limit the slip control has been further optimised.

\section{B. Gear Ratio}

As stated before, the gear ratio $r_{\mathrm{g}}$ of the mechanical CVT systems is geometrically limited. This way, standstill of the outer rotor is not possible at rotating inner rotor, nor is reversing of the outer rotor with respect to the inner rotor. This consequently results in the need for a torque converter or clutch with reversing unit or a planetary gear set. For the EVT in this paper, the gear ratio lower limit is negative, so that both standstill and reversing are inherently possible. However note that negative gear ratios $\left(r_{\mathrm{g}}<0\right)$ and oversynchronous rotations $\left(r_{\mathrm{g}}>1\right)$ will result in circulating power.

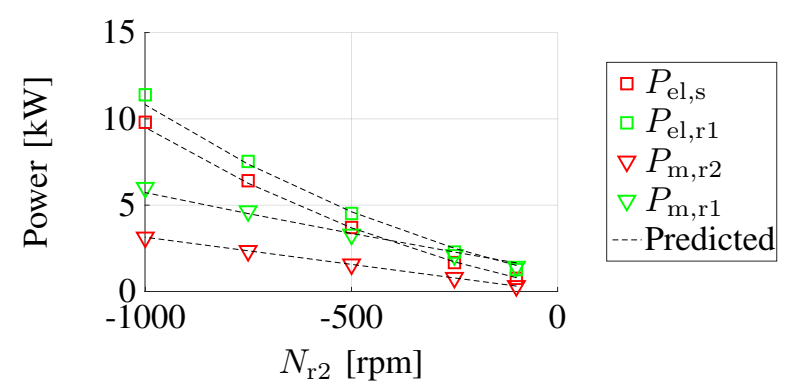

Fig. 16: Measured and predicted power flow at at $T_{\mathrm{r} 2}=-30$ $\mathrm{Nm}$ and input speed $N_{\mathrm{r} 1}=1000 \mathrm{rpm}$.

Power flow in oversynchronous operation was shown in Fig. 13a where the input speed $N_{\mathrm{r} 1}=2000 \mathrm{rpm}$, while the output speed was increased untill $N_{\mathrm{r} 2}=3000 \mathrm{rpm}$. It was noted in the figure that the converted electrical power increases quadratically with the output speed. A similar figure is shown here in Fig. 16 for reversing operation. The converted electrical power increases again quadratically and beyond the converted mechanical power. Consequently, the oversynchronous and reversing regions are limited in power, particularly by the choice of the inverters, as described into detail in section III and the torque ratings of both stator and inner rotor, as was discussed in section IV. In practice, reversing or standstill will only use low powers.

\section{Overload Protection and Overload Capability}

Finally, the EVT has the advantage that no mechanical connection exists between input and output shaft. This means that an inherent overload protection between both shafts exists eliminating the need for a torque fuse. Also vibrations between both shafts are inherently damped. The other way around, the EVT can also produce an overload torque which is thermally limited in time, as can also be seen in Table I. This feature, which can be used for short (but hard) accelerations, is an advantage compared to mechanical transmissions for which the rated torque is equal to the maximum torque and is limited by the maximum allowable clamping force [6]. 


\section{CONCLUSIONS}

In this paper, it has been shown that an EVT can be used as continuously variable transmission with electrical power takeoff (PTO). The input power is split into an electromagnetic and electrical path. Without PTO, the fraction of the total power converted electrically, is ideally a linear function of the outer rotor speed, decreasing towards synchronisation of both rotors. Measurements show that the EVT has comparable efficiencies as the toroidal CVT. Because however the hydraulic pump losses of the latter are not considered, all in all the EVT will have a better efficiency than the toroidal CVT. Compared to the belt CVT, the EVT shows an efficiency increase of more than $10 \%$ over the entire measurement region. The EVT has the additional advantage that no additional clutch or torque converter is required. Moreover it has inherent overload protection, fast dynamics and high overload capability. Therefore, the EVT seems a viable alternative to consider for mechanical automotive CVTs.

\section{ACKNOWLEDGMENT}

With thanks to the company EVT BV for designing and building the prototype PM EVT machine.

\section{REFERENCES}

[1] K. Ishikawa, E. Inoue, and T. Imanishi, "Research of cvt efficiency - comparison of a toroidal cvt and a belt cvt," Review of Automotive Engineering, vol. 29, no. 4, pp. 479-483, July 2008.

[2] F. van der Sluis, T. van Dongen, G.-J. van Spijk, A. van der velde, and A. van Heeswijk, "Efficiency optimization of the pushbelt cvt," in SAE Technical Paper. SAE International, April 2007.

[3] J. P. Newall, D. M. Nicolson, A. P. Lee, and S. P. Evans, "Development and assessment of traction fluids for use in toroidal (ivt) transmissions,' in SAE Technical Paper. SAE International, March 2002.

[4] A. P. Lee, "Full-toroidal traction drive variator material and fluid durability," SAE Int. J. Engines, vol. 4, pp. 2135-2141, April 2011.

[5] T. Inoue and H. Nishii, "Study on wide ratio range toroidal ivt," in SAE Technical Paper. SAE International, August 2011.

[6] F. Verbelen, S. Derammelaere, P. Sergeant, and K. Stockman, "Half toroidal continuously variable transmission: Trade-off between dynamics of ratio variation and efficiency," Mechanism and Machine Theory, vol. 107, pp. 183 - 196, 2017

[7] E. Skjong, T. A. Johansen, M. Molinas, and A. Sorensen, "Approaches to economic energy management in diesel-electric marine vessels," IEEE Trans. Transport. Electrific., 2017.

[8] A. Veksler, T. A. Johansen, R. Skjetne, and E. Mathiesen, "Thrust allocation with dynamic power consumption modulation for dieselelectric ships," IEEE Trans. Control Syst. Technol., vol. 24, no. 2, pp. 578-593, March 2016.

[9] T. Letrouve, W. Lhomme, J. Pouget, and A. Bouscayrol, "Different hybridization rate of a diesel-electric locomotive," in 2014 IEEE Vehicle Power and Propulsion Conference (VPPC), Oct 2014, pp. 1-6.

[10] X. Zhang, C. T. Li, D. Kum, and H. Peng, "Prius and volt: Configuration analysis of power-split hybrid vehicles with a single planetary gear,' IEEE Trans. Veh. Technol., vol. 61, no. 8, pp. 3544-3552, Oct 2012.

[11] K. T. Chau, C. C. Chan, and C. Liu, "Overview of permanent-magnet brushless drives for electric and hybrid electric vehicles," IEEE Trans. Ind. Electron., vol. 55, no. 6, pp. 2246-2257, June 2008.

[12] I. Boldea, L. N. Tutelea, S. I. Deaconu, and F. Marignetti, "Dual rotor single- stator axial air gap pmsm motor/generator drive for hevs: A review of comprehensive modeling and performance characterization,' in 2012 Electrical Systems for Aircraft, Railway and Ship Propulsion, Oct 2012, pp. 1-8.

[13] L. N. Tutelea, S. I. Deaconu, and I. Boldea, "Design and fem validation for an axial single stator dual rotor pmsm," in IECON 2012 - 38th Annual Conference on IEEE Industrial Electronics Society, Oct 2012, pp. 2929-2935.
[14] Y. H. Yeh, M. F. Hsieh, and D. G. Dorrell, "Different arrangements for dual-rotor dual-output radial-flux motors," IEEE Transactions on Industry Applications, vol. 48, no. 2, pp. 612-622, March 2012.

[15] M. Hoeijmakers and J. Ferreira, "The electric variable transmission," IEEE Trans. Ind. Appl., vol. 42, no. 4, pp. 1092-1100, July 2006.

[16] H. Cai and L. Xu, "Modeling and control for cage rotor dual mechanical port electric machine part i: Model development," IEEE Trans. Energy Convers., vol. 30, no. 3, pp. 957-965, September 2015.

[17] _ _ "Modeling and control for cage rotor dual mechanical port electric machine part ii: Independent control of two rotors," IEEE Trans. Energy Convers., vol. 30, no. 3, pp. 966-973, September 2015.

[18] J. Druant, F. D. Belie, P. Sergeant, and J. Melkebeek, "Field-oriented control for an induction-machine-based electrical variable transmission," IEEE Trans. Veh. Technol., vol. 65, no. 6, pp. 4230-4240, June 2016.

[19] X. Sun and M. Cheng, "Thermal analysis and cooling system design of dual mechanical port machine for wind power application," IEEE Trans. Ind. Electron., vol. 60, no. 5, pp. 1724-1733, May 2013.

[20] Y. Zhu, M. Cheng, W. Hua, and B. Zhang, "Sensorless control strategy of electrical variable transmission machines for wind energy conversion systems," IEEE Trans. Magn., vol. 49, no. 7, pp. 3383-3386, July 2013.

[21] E. Nordlund and C. Sadarangani, "The four-quadrant energy transducer," in Conference Record of the Industry Applications Conference, 2002. 37th IAS Annual Meeting, vol. 1, Oct 2002, pp. 390-397 vol.1.

[22] Y. Liu, D. Cheng, Y. Sui, J. Bai, C. Tong, and W. Tong, "Magnetic system study of a compound-structure permanent-magnet synchronous machine for hevs," IEEE Trans. Ind. Appl., vol. 48, no. 6, pp. 1797 1807, November 2012.

[23] P. Zheng, R. Liu, Q. Wu, J. Zhao, and Z. Yao, "Magnetic coupling analysis of four-quadrant transducer used for hybrid electric vehicles," IEEE Trans. Magn., vol. 43, no. 6, pp. 2597-2599, June 2007.

[24] M. Hoeijmakers, "Rotating electromechanical converter," Patent US 9018863 , April 28, 2015.

[25] J. Druant, H. Vansompel, F. D. Belie, J. Melkebeek, and P. Sergeant, "Torque analysis on a double rotor electrical variable transmission with hybrid excitation," IEEE Trans. Ind. Electron., vol. 64, no. 1, pp. 60-68, Jan 2017.

[26] Y. Cheng, R. Trigui, C. Espanet, A. Bouscayrol, and S. Cui, "Specifications and design of a pm electric variable transmission for toyota prius ii," IEEE Trans. Veh. Technol., vol. 60, no. 9, pp. 4106-4114, November 2011.

[27] —_, "Specifications and design of a pm electric variable transmission for toyota prius ii," IEEE Trans. Veh. Technol.., vol. 60, no. 9, pp. 41064114, November 2011.

[28] E. Vinot, R. Trigui, Y. Cheng, C. Espanet, A. Bouscayrol, and V. Reinbold, "Improvement of an evt-based hev using dynamic programming," IEEE Trans. Veh. Technol., vol. 63, no. 1, pp. 40-50, January 2014.

[29] Y. Cheng, K. Chen, C. C. Chan, A. Bouscayrol, and S. Cui, "Global modeling and control strategy simulation for a hybrid electric vehicle using electrical variable transmission," in 2008 IEEE Vehicle Power and Propulsion Conference, Sept 2008, pp. 1-5.

[30] J. Druant, F. D. Belie, P. Sergeant, and J. Melkebeek, "Power flow in an induction machine based electrical variable transmission," in 2016 International Symposium on Power Electronics, Electrical Drives, Automation and Motion (SPEEDAM), June 2016, pp. 1197-1202.

[31] L. Xu, Y. Zhang, and X. Wen, "Multioperational modes and control strategies of dual-mechanical-port machine for hybrid electrical vehicles,” IEEE Trans. Ind. Appl., vol. 45, no. 2, pp. 747-755, March 2009.

[32] J. Druant, H. Vansompel, F. D. Belie, and P. Sergeant, "Optimal control for a hybrid excited dual mechanical port electric machine," IEEE Trans. Energy Convers., vol. PP, no. 99, pp. 1-1, 2017.

[33] E. Barbisio, F. Fiorillo, and C. Ragusa, "Predicting loss in magnetic steels under arbitrary induction waveform and with minor hysteresis loops," IEEE Trans. Magn., vol. 40, no. 4, pp. 1810-1819, July 2004.

[34] G. Bertotti, Hysteresis in magnetism: for physicists, materials scientists, and engineers, A. Pr, Ed., 1998.

[35] J. Druant, H. Vansompel, F. D. Belie, and P. Sergeant, "Loss identification in a double rotor electrical variable transmission," IEEE Trans. Ind. Electron.

[36] T. Imanishi and H. Machida, "Development of powertoros unit halftoroidal cvt (2) comparison between halftoroidal and full-toroidal cvts," Motion and Control, 2001

[37] H. Tanaka, N. Toyoda, T. Imanishi, and H. Machida, "Development of a 6 power-roller half-toroidal cvt - mechanism and efficiency," in International Continuously Variable and Hybrid Transmission Congress, September 2004

[38] B. Bonsen, "Efficiency optimization of the push-belt cvt by variator slip control," Ph.D. dissertation, Technische Universiteit Eindhoven, 2006. 


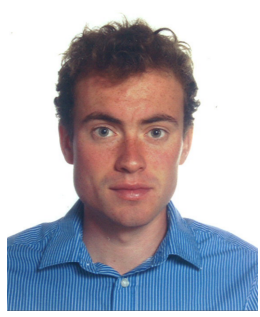

Joachim Druant was born in leper, Belgium in 1990. He received the M.Sc. degree in electromechanical engineering in 2013 from Ghent University, Ghent, Belgium. Since then, he has been with the Electrical Energy Laboratory (EELAB), Department of Electrical Energy, Metals, Mechanical Constructions and Systems of Ghent University and is currently working towards the Ph.D. degree in electromechanical engineering. In 2014, he was awarded a Ph.D. Fellowship from the Research FoundationFlanders (FWO). His present research interests include digital control of converter-fed electrical machines, fault tolerant control, and modeling and control on electrical variable transmissions.

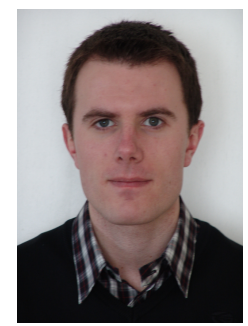

Hendrik Vansompel was born in Belgium in 1986. He received the Master and the PhD degree in electromechanical engineering from Ghent University, Belgium, in 2009 and 2013, respectively. Currently he is working at the Department of Electrical Energy, Metals, Mechanical Constructions and Systems, Ghent University, as a postdoctoral research assistant. His interests include the design and control of electrical drives.

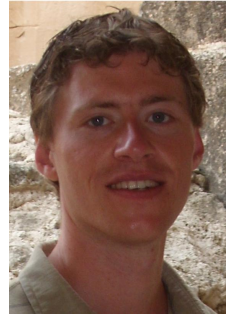

Frederik De Belie was born in Belgium in 1979. He received the Master degree in electromechanical engineering from Ghent University, Ghent, Belgium, in 2002, and the Ph.D. degree in March 2010. He's currently a postdoctoral assistant in the Electrical Energy, Metals, Mechanical Constructions and Systems Department of the Ghent University. His present research interests include modelling theory and control-system theory applied to electrical drives and, in particular, self-sensing control of syn-

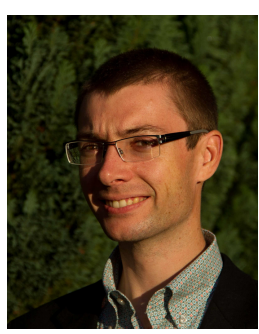

Peter Sergeant received the M.Sc. degree in electromechanical engineering in 2001, and the $\mathrm{Ph} . \mathrm{D}$. degree in engineering sciences in 2006 both from Ghent University, Ghent, Belgium. In 2001, he became a researcher at the Electrical Energy Laboratory of Ghent University. He became a postdoctoral researcher at Ghent University in 2006 (postdoctoral fellow of the Research Foundation - Flanders) and at Ghent University College in 2008. Since 2012, he is associate professor at Ghent University. His current research interests include numerical methods in combination with optimization techniques to design nonlinear electromagnetic systems, in particular, electrical machines for sustainable energy applications. 